\title{
Conservation genomics of an Australian orchid complex with implications for the taxonomic and conservation status of Corybas dowlingii
}

Natascha D. Wagner1,2, Mark A. Clements3,4, Lalita Simpson1,5, Katharina Nargar1,6,*

1Australian Tropical Herbarium, James Cook University, GPO Box 6811, Cairns, QLD 4878, Australia

2Dept. of Systematics, Biodiversity and Evolution of Plants, Albrecht Haller Institute for Plant Sciences, Georg August University of Goettingen, Untere Klarspüle 2, 37073 Goettingen,

Germany

3Centre for Australian National Biodiversity Research, GPO Box 1700, Canberra, ACT 2601, Australia

4Australian National Botanic Gardens, GPO Box 1777, Canberra, ACT 2601, Australia

5College of Science and Engineering, James Cook University, PO Box 6811, Cairns, 4870

QLD, Australia

6National Research Collections Australia, Commonwealth Industrial and Scientific Research Organisation (CSIRO), GPO Box 1700, Canberra, ACT 2601, Australia

*Corresponding author: katharina.nargar@ csiro.au

\section{ORCID of authors}

Natascha Wagner: 0000-0001-6623-7623

Mark A. Clements: 0000-0001-2345-6789

Lalita Simpson: 0000-0003-3165-881X

Katharina Nargar: 0000-0002-0459-5991

\section{Acknowledgments}

The authors thank the Office of Environment and Heritage (Dept. of Planning and

Environment, New South Wales, Australia) for financial support of the study and for granting of collection permits (NSW National Parks \& Wildlife Service Scientific Licence SL100750 and Forest NSW Special Purpose Permit for Research XX51121). We thank R. Autin, C. Broadfield, J. Cootes, I. Hutton, W. Probert, J. Moye, J. Riley, A. Stephenson, R. Thomson and J. Turner for contributing plant material to the study. The authors acknowledge the use of lab services and sequencing facilities of the Australian Genomic Research Facility (AGRF). 


\begin{abstract}
This study assessed genomic diversity in an Australian species complex in the helmet orchids to clarify taxonomic delimitation and conservation status of the threatened species Corybas dowlingii, a narrow endemic from southeast Australia. Taxonomic delimitation between the three closely related species $C$. aconitiflorus, $C$. barbarae, and $C$. dowlingii has been mainly based on floral traits which exhibit varying degrees of overlap, rendering species delimitation in the complex difficult. Genomic data for the species complex was generated using doubledigest restriction-site associated DNA (ddRAD) sequencing. Maximum likelihood, NeighborNet, and Bayesian structure analyses showed genetic differentiation within the species complex and retrieved genomic signatures consistent with hybridisation and introgression between $C$. aconitiflorus and C. barbarae, and an intermediate genetic position of $C$. dowlingii indicating a hybrid origin of the species. The genetic structure analysis showed varying levels of genetic admixture for several $C$. aconitiflorus, $C$. barbarae, and $C$. dowlingii samples, thus further corroborating the presence of hybridisation and introgression within the species complex. The taxonomic status of $C$. dowlingii D.L.Jones was revised to $C$. $\times$ dowlingii D.L.Jones stat. nov. to reflect its hybrid origin. The conservation status of $C . \times$ dowlingii was assessed based on key ecological and ethical aspects, and recommendations made regarding its conservation status in Australian conservation legislation.
\end{abstract}

Keywords: Australasia, Species delimitation, ddRAD sequencing, Diurideae, Taxonomy, Orchidaceae

\title{
Introduction
}

Orchidaceae is the world's second largest flowering plant family, comprising over 27,800 species and 736 genera (Chase et al. 2015; (List 2018) that display extraordinary morphological and ecological diversity. Orchids inhabit a wide range of terrestrial and epiphytic habitats worldwide exhibiting their highest species diversity in the tropics (Cribb et al. 2003). However, many orchid species possess only narrow distributions, rendering them vulnerable to threats such as climate change, habitat destruction or over-exploitation (Cribb et al. 2003).

In the Australian flora, orchids rank within the ten largest angiosperm families, and exhibit a high level of endemicity with about $90 \%$ of Australian native orchids found nowhere else (Govaerts et al. 2017). Orchids constitute over $15 \%$ of Australia's threatened plant species and over one third of Australia's critically endangered plants (EPBC 1999). Over the last 
decade, new orchid species have been described at a rate of approximately 500 species per year worldwide (Chase et al. 2015). However, species delimitation in orchids is often challenging, which is reflected by the large number of taxonomic synonyms in orchids (Govaerts et al. 2017). In Australia, the number of orchid species recognised for the country has increased from around 900 species to more than 1,300 over the past two decades (Hopper 2009; Govaerts et al. 2017). This increase has been partly attributed to the discovery and description of new species and partly to the application of narrower species concepts elevating many infraspecific taxa to species level (Hopper 2009; Chase et al. 2015). The resulting uncertainties in the taxonomic status of many Australian orchid species greatly hamper effective conservation management and allocation of scarce resources.

The Corybas aconitiflorus complex (Acianthinae, Diurideae) is a group of small geophytic, colony-forming herbs with globose tubers. They possess a single heart-shaped leaf and a solitary flower with an enlarged hood-shaped dorsal sepal that imparts the impression of a helmet, hence the vernacular name 'helmet orchids' (Pridgeon et al. 2001). The flowers are mostly dull-coloured with shades of reddish or brownish purple, sometimes white to pinkish, and are pollinated by fungus gnats of the family Mycetophilidae Newman 1834 (Pridgeon et al. 2001). As in most orchids, the fruit is a dehiscent capsule with numerous dust-like seeds.

Previous molecular studies provided insights into phylogenetic relationships in Corybas (Clements et al. 2002, Lyon 2014) and identified an unresolved clade of four closely related species which constitute the $C$. aconitiflorus complex: three of the species are endemic to Australia (C. aconitiflorus Salisb., C. barbarae D.L.Jones, and C. dowlingii D.L.Jones) and one to Java (C. imperiatorus (J.J.Sm.) Schltr.) (Lyon 2014). Among the Australian species of the complex, C. aconitiflorus and C. barbarae are locally common and widespread, extending over $2,000 \mathrm{~km}$ along the Australian east coast, broadly in sympatry (AVH 2018). In contrast, $C$. dowlingii is narrowly endemic in New South Wales, extending ca. $100 \mathrm{~km}$ from Bulahdelah north of Newcastle to Freemans Waterhole south of Newcastle (Jones 2004; AVH 2018)), and occurs within the distribution range of both $C$. aconitiflorus and C. barbarae (AVH 2018). Corybas dowlingii is listed as vulnerable species at federal level (EPBC 1999) and as endangered under the New South Wales Threatened Species Conservation Act (1995) due to its highly restricted distribution and anthropogenic pressures on its habitat.

Previous molecular systematic studies in Diurideae based on the internal transcribed spacer (ITS) confirmed the taxonomic placement of Corybas within subtribe Acianthinae (Kores et al. 2001; Clements et al. 2002), and a combined phylogenetic analysis of ITS and 68 morphological characters in Acianthinae showed the C. aconitiflorus complex as unresolved polytomy 
together with C. cerasinus, an endemic species from northern Queensland (Australia) and New Zealand endemic $C$. cheesemanii (Clements et al. 2002). However, C. dowlingii was not described at the time of the study of (Clements et al. 2002). A molecular study in Corybas based on five plastid and three nuclear markers further resolved phylogenetic relationships in the genus and showed C. aconitiflorus, C. barbarae, C. dowlingii, and C. imperatorius as a clade, however relationships among these species remained unclear due to lack of statistical support (Lyon 2014). While sequence divergence among the three Australian species was shallow, $C$. imperiosus was situated on a long branch in the phylogenetic tree reconstruction (Lyon 2014). Morphologically, $C$. dowlingii is only weakly differentiated from $C$. aconitiflorus and $C$. barbarae. Its flowers are dark purplish red, and the labellum is of the same colour with some whitish areas and sparse bristles (Jones 2004, 2006). It is distinguished from the other two species mainly by differences in flower size and colouration, and a later, yet overlapping flowering time. Corybas aconitiflorus has greyish to reddish purple flowers that are smaller than in C. dowlingii, and has a whitish labellum with sparse tiny bristles (Jones 2004, 2006). Corybas barbarae has white to pinkish flowers of a similar size to $C$. dowlingii and possesses a white labellum covered in dense bristles (Jones 2004, 2006). Due to the low genetic divergence within the $C$. aconitiflorus complex observed in previous molecular studies (Clements et al. 2002; Lyon 2014), and the weak morphological differentiation between the three species with partly overlapping character states, further molecular studies with more informative molecular markers are required to assess species delimitation within the complex and to re-evaluate the conservation status of $C$. dowlingii.

Recent advances in high-throughput DNA sequencing and bioinformatics offer powerful genomic approaches to resolve complex inter- and intraspecific relationships at unprecedented resolution, facilitating the re-assessment of taxonomic concepts in species complexes and the conservation status of rare and threatened species (Ahrens et al. 2017; Bateman et al. 2018; Coates et al. 2018; Cozzolino et al. 2019; Taylor and Larson 2019).

Restriction-site-associated DNA sequencing (Baird et al. 2008) is a next generation sequencing method based on reduced representation library sequencing, which is a cost-effective method to obtain genome-scale data from non-model organisms (Davey et al. 2011; Lemmon and Lemmon 2013). For RADseq, genomic DNA is digested using one or two restriction enzymes (ddRAD). DNA fragments of a certain size range are selected as subset for library preparation and then subjected to high throughput sequencing (Miller et al. 2007; Baird et al. 2008; Peterson et al. 2012)(Miller et al. 2007; Lemmon and Lemmon 2013). RADseq has been successfully used to clarify inter- and intraspecific relationships and to assess taxonomic delimitation in 
species complexes, including in orchids (Brandrud et al., 2019a, b; Wagner et al. 2013; Jones et al. 2013; Eaton and Ree 2013; Escudero et al. 2014; Takahashi et al. 2014; Mort et al. 2015; Herrera and Shank 2016; Beheregaray et al. 2017; Bateman et al. 2018; Hipp et al. 2018). The aims of this study were to assess genetic diversity and structure within the $C$. aconitiflorus complex based on genomic data derived from double-digest restriction-site associated DNA sequencing (ddRADseq) in order to clarify species delimitation within the complex and to evaluate the taxonomic and conservation status of the narrow endemic $C$. dowlingii.

\section{Materials and methods}

\section{Material studied}

In total, 72 samples were included in the study, of which 70 samples from the $C$. aconitiflorus complex: C. aconitiflorus (24 samples, 9 localities), C. barbarae (32 samples, 5 localities), and C. dowlingii (14 samples, 2 localities). Corybas pruinosus (A.Cunn.) Rchb.f. (2 samples) was included as outgroup based on Clements et al. (2002). Sampling focussed on the southeastern distribution of the $C$. aconitiflorus complex to which $C$. dowlingii is endemic and extended from the restricted distribution of $C$. dowlingii (between Port Macquarie and Newcastle, New South Wales) ca. $300 \mathrm{~km}$ northwards to the border between New South Wales and Queensland (Uralba), ca. 1,200 km southwards to Tasmania (Ulverstone), and ca. $600 \mathrm{~km}$ eastwards to Lord Howe Island. For each population, one herbarium voucher was taken per species sampled and lodged at CANB. Sampling locations are shown in Fig. 1 and further details on plant material studied are provided in Tab. 1.

\section{DNA extraction, ddRAD library preparation, and sequencing}

Total DNA was extracted from silica-dried leaf material using a modified CTAB protocol (Weising et al. 2005). DNA quality was assessed using a spectrophotometer (NanoDrop, Thermo Scientific) and gel electrophoresis on $2 \%$ agarose gels, and DNA quantity was determined using a Qubit fluorometer (Thermo Fisher Scientific).

Double-digest restriction-site associated DNA (ddRAD) sequencing libraries were prepared following Peterson et al. (Peterson et al. 2012). During the initial establishment phase, double restriction enzyme digests of genomic DNA were carried out for three Corybas samples $(C$. aconitiflorus CNS_G04732, C. barbarae CNS_G04671, C.dowlingii CNS_G04727) testing eight different restriction enzyme combinations comprising a six base cutter (PstI or EcoRl) and a four base cutter (MspI, HypCH4VI, MseI or NIaIII). Digests were followed by ligation 
of barcoded adapters compatible with the restriction site overhang, bead purification, and amplification of the non-size selected sequencing library via PCR. Sequencing libraries were evaluated based on gel electrophoresis using TapeStation (Agilent Technologies, Santa Clara, CA, USA) to select the most suitable restriction enzyme combination that indicated the least amount of likely repetitive sequences. After this initial test, the enzyme combination Pst I and NlaIII was selected for the three Corybas samples, including ligation of barcoded adapters, purification of the pooled digested-ligated fragments followed by size selection via Blue Pippin (Sage Science, Beverly, Massachusetts, USA) for two ranges, a narrow (280-342bp) and a wide (280-375bp) range. The two pooled libraries were amplified via PCR with indexed primers, and sequenced on the Illumina MiSeq platform for single-ended, $160 \mathrm{bp}$ reads at the Australian Genome Research Facility (AGRF; Melbourne, Victoria, Australia). The sequencing data for the narrow and wide size selected libraries was analysed using the Stacks pipeline (Catchen et al. 2011, 2013) to assess the number of ddRAD loci per sample, the average coverage per sample, and the number of unique and shared ddRAD loci across the three samples. The narrow library yielded between 116,991 and 276,091 ddRAD loci per sample and an average coverage of 6.5-9.2 per sample and the wide library resulted in 85,229 to 203,174 ddRAD loci per sample and an average coverage of 6.4-9.4 per sample. The narrow size selection yielded a higher number of shared ddRAD loci across the three samples than the wider size selected sequencing library. Based on the evaluation of two pooled libraries, the narrow size selection was chosen for ddRAD sequencing for the complete sample set. Quality and reproducibility of libraries and DNA sequencing were assessed by running five samples in duplicate (6.9\% of all samples). Multiplexed libraries were sequenced on one lane of a NextSeq500 sequencing platform (Illumina Inc., San Diego, CA, USA) as single-ended, $150 \mathrm{bp}$ reads at the Australian Genome Research Facility (AGRF; Melbourne, Victoria, Australia).

\section{Bioinformatics and data filtering}

Quality of the sequence reads was examined using FastQC v.0.11.5 (Andrews 2010). Raw sequences were demultiplexed, trimmed and further processed using the ipyrad pipeline v.0.6.15 (Eaton and Overcast 2016). In an initial filtering step, reads with more than five low quality bases (Phred quality score < 20) were excluded from the data set. The phred quality score offset was set to 33 . The strict adapter trimming option was selected and a minimum read length of $35 \mathrm{bp}$ after trimming was chosen to retain a read in the dataset. After these qualityfiltering steps, the reads were clustered within and across samples by similarity of $85 \%$ using 
the vclust function in VSEARCH (Edgar 2010). The alignment was carried out using MUSCLE (Edgar 2004) as implemented in ipyrad. Clusters with less than six reads were excluded in order to ensure accurate base calls. The resulting clusters represent putative RAD loci shared across samples. A maximum number of five uncalled bases ('Ns') and a maximum number of eight heterozygote sites ('Hs') was allowed in the consensus sequences. The maximum number of SNPs within a locus was set to ten and the maximum number of indels per locus to five. For the sample set including all accessions of the C. aconitiflorus complex as well as two accessions of $C$. pruinosus as outgroup ipyrad runs for two different datasets were performed, i.e. based on loci shared by 20 individuals $(\mathrm{m} 20)$ and on loci shared by 70 individuals $(\mathrm{m} 70)$. Additionally, the same settings were used for ipyrad runs excluding the outgroup (C. pruinosus, 2 samples). The datasets generated and analysed during the current study are available at CSIRO's Data Access Portal, [DOI will be provided in published manuscript].

\section{Phylogenomic and genetic structure analysis}

Phylogenetic relationships were inferred using maximum likelihood (ML) based on concatenated alignments applying the GTR $+\Gamma$ model of nucleotide substitution using RAXML v.8.2.4 (Stamatakis 2014) for both datasets (m20, $\mathrm{m} 70)$ including the outgroup. Statistical support was assessed via a rapid bootstrapping with 100 pseudoreplicates (Stamatakis et al. 2008)(Stamatakis et al. 2008) under the same ML analysis settings.

NeighborNet analysis of the C. aconitiflorus complex was carried out in SplitsTree v.4.13 (Huson and Bryant 2006) using the unlinked SNP output of the m20dataset excluding the outgroup. The unlinked SNPs represent one randomly chosen SNP per locus and are therefore considered independend markers. Equal angle split transformation and uncorrelated P distance were selected for the NeighborNet analysis.

Genetic structure of the C. aconitiflorus complex was analysed using the Bayesian Markov Chain Monte Carlo (MCMC) clustering method implemented in the program Structure v.2.3.4 (Pritchard et al. 2000) based on both datasets (m20, m70) excluding the outgroup. For both datasets, the Structure output format of unlinked SNPs (.ustr) of the ipyrad pipeline was used as input file. Data analysis assumed correlated allele frequencies and admixture and prior population information was not included in the analysis (Hubisz et al. 2009). After preliminary runs with a smaller number of cycles and because of computational limitations, we conducted three independent runs for each value of $\mathrm{K}=3-8$ with 100,000 MCMC cycles 
following a burn-in of 10,000 MCMC cycles for the final analyses. The range of K-values was chosen based on the number of expected species (3) and number of eight observed clades in the RAxML analysis. The number of genetic groups best fitting the dataset was determined using the delta K method (Evanno et al. 2005) as implemented in Structure Harvester (Earl and vonHoldt 2012).

\section{Results}

An average of 2,98 $( \pm 1,01)$ filtered Illumina reads per sample were used for the analyses. A total number of 362,412 pre-filtered loci passed the ipyrad pipeline. After subsequent filtering steps, the number of retained loci for the final datasets varied between 3,597 (m70) and 12,420 (m20) for the datasets including the outgroup, and between 4,293 (m70) and 14,915 (m20) loci for the datasets excluding the outgroup. The latter included 60,489 SNPs (see Table 2). The average read depth per locus was $20.87( \pm 4.01)$ reads. Further statistics of the ddRAD datasets are summarized in Tab. 2 .

\section{Maximum likelihood analysis}

The ML tree reconstruction based on the $\mathrm{m} 20$ dataset including the outgroup retrieved the $C$. aconitiflorus complex as monophyletic group with maximum bootstrap support (BS 100) (Fig. 2). Genetic divergence between the C. aconitiflorus complex and C. pruinosus was considerably higher than within species as indicated by branch length (Fig. 2). Within the C. aconitiflorus complex, the ML reconstruction did not provide support for the monophyly of the three species $C$. aconitiflorus, C. barbarae, and C. dowlingii (Fig. 2).

A well-supported cluster (BS 96) comprising individuals from C. barbarae from North Coast (Broken Bago) was depicted as branching off first, followed by a second well supported cluster of C. barbarae (BS 100) from North Coast (Broken Bago). The next dichotomy showed one branch unifying individuals from $C$. barbarae from North Coast (Queens Lake and Uralba) and a highly supported branch (BS 97) harbouring individuals from C. barbarae, C. dowlingii and C. aconitiflorus. Within the latter branch, the first two diverging clusters were formed by individuals of $C$. dowlingii from North Coast (Broken Bago), both receiving high support (BS 92 and BS 94, respectively). The next diverging branch showed a dichotomy with one branch that harboured a moderately supported cluster (BS 85) unifying individuals of $C$. aconitiflorus from North Coast and South Coast, respectively (Uralba and Nowra) next to a highly supported cluster (BS 100) comprising individuals of $C$. barbarae and $C$. 
dowlingii. The latter cluster split into two highly supported clusters (BS 100), one with all individuals of $C$. barbarae from Lord Howe Island and the other with individuals of $C$. dowlingii from North Coast (Lake Cathie).

The second branch of the dichotomy was well supported (BS 90) and comprised the remaining samples of C. aconitiflorus from Central Coast and South Coast (Sydney and Nowra), all C. aconitiflorus samples from south Victoria (Colquhoun, Belgrave, Orbost, Shallow Inlet, Wilson Promontory) and Tasmania (Ulverstone) (Fig. 2). Within the latter, the C. aconitiflorus individuals from south Victoria and Tasmania formed a weakly supported subcluster (BS 60).

The ML analysis of the m70 dataset yielded congruent results for highly supported relationships and differed in topology for nodes that remained unsupported or received low statistical support in the analysis. Results of the ML analysis of the m70 dataset are presented in Online Resource 1.

\section{NeighborNet analysis}

The NeighborNet network based on 13,708 unlinked SNPs of the m20 dataset of the $C$. aconitiflorus complex showed one large group comprising C. barbarae from the Australian mainland, one large group comprising $C$. aconitiflorus, and in intermediate position within the NeighborNet C. barbarae from Lorde Howe Island and C. dowlingii (Fig. 3). However, genetic distances between the branches in the NeighborNet were overall low and exhibited patterns of reticulation. Subgroups within the network were largely consistent with well supported clusters found in the ML analysis.

Within the large group of $C$. barbarae from the Australian mainland, the NeighborNet diagram showed three branches that harboured individuals from Queens Lake (North Coast), two branches that comprised individuals from Broken Bago (North Coast) and one branch with C. barbarae from North Coast (Uralba). Corybas barbarae samples from Lord Howe Island formed a group that clustered together with $C$. dowlingii from Lake Cathie (North Coast), which corresponded to the relationships found in the ML analysis. Within the $C$. aconitiflorus group, samples from south Victoria and Tasmania formed a weakly differentiated subgroup, whereas C. aconitiflorus samples from NSW (Nowra, Sydney, Uralba) were found in more proximate position to C. dowlingii from Broken Bago, corresponding to relationships found in the ML analysis (Fig. 3). The NeigbourNet analysis based on the m70 dataset yielded highly congruent results to the analysis of the m20 dataset and are provided in Online Resource 2. 


\section{Genetic structure analysis}

In the following we report on the results of the Bayesian cluster analysis with Structure based on the m70 SNP dataset, which comprised 4,066 unlinked SNPs and a lower proportion of missing data than the $\mathrm{m} 20$ dataset as missing data can introduce biases to Structure analyses. For the m70 dataset, the best number of genetic groups $(\mathrm{K})$ as determined by the modal $\Delta \mathrm{K}$ distribution was $\mathrm{K}=7$. The resulting bar plot (Fig. 4) showed several distinct genetic clusters and samples with varying degrees of genetic admixture. The genetic clusters retrieved by the Structure analysis did not correspond to current species concepts in the C. aconitiflorus complex.

The majority of $C$. barbarae samples from the mainland fell into three genetically distinct clusters that exhibited a low or no signal of genetic admixture. Two of these clusters unified samples from North Coast (Broken Bago), which also formed two well-supported clades in the ML analysis and two distinct branches in the NeighborNet analysis. The third C. barbarae cluster in the Structure analysis comprised a group of eleven samples from North Coast (Queens Lake), which were also found as highly supported cluster in the ML analysis and as a distinct branch in the NeighborNet analysis. The $C$. barbarae samples from Lord Howe Island and the $C$. dowlingii samples from Lake Cathie together formed another genetically distinct cluster. These samples were also found as highly supported clade in the ML analysis and in the NeighborNet analysis. For the remaining C. barbarae samples from North Coast (Queens Lake) and from North Coast (Uralba) the Structure analysis indicated high levels of genetic admixture (Fig. 4). High levels of genetic admixture were also found for $C$. dowlingii from Broken Bago (North Coast) and several samples of $C$. aconitiflorus from South Coast (Nowra). The remaining C. aconitiflorus samples from Central Coast and South Coast (Sydney and Nowra) displayed moderate levels of genetic admixture, whereas the $C$. aconitiflorus samples from south Victoria and Tasmania displayed low levels or no genetic admixture in the Structure bar plot (Fig. 4). The results from the Structure analysis based on the $\mathrm{m} 20$ dataset are provided in Online Resource 3.

\section{Discussion}

Accurate delimitation of species and infraspecific taxa is of critical importance to conservation biology as these are commonly used measures of biodiversity (Coates et al. 2018). However, taxon delimitation still heavily relies on the evaluation of morphological and ecological traits, which can be subject to convergent or parallel evolution and environmental 
plasticity. Further, taxonomic boundaries can be blurred through hybridisation and introgression, which are frequently observed phenomena among closely related orchid species (Dressler 1981; Cozzolino et al. 2006; Pinheiro et al. 2010; Nauheimer et al. 2018).

Recent advances in high throughput sequencing and statistical analyses now facilitate unprecedented fine-scale resolution of inter- and intraspecific relationships with detailed insights into genetic diversity and population structure. Hence, these approaches provide critical genomic data to evaluate taxonomic concepts in species complexes and to inform the development of effective conservation strategies for threatened species. Reduced representation library sequencing approaches, such as RADseq, ddRADseq and genotypingby-sequencing (GBS), have proven to be powerful tools for disentangling complex relationships and delimiting taxonomic boundaries in orchids (Ahrens et al. 2017; Bateman et al. 2018; Brandrud et al. 2019a). Here, we present a study using more than 13,000 SNPs to unravel the complex relationships in the $C$. aconitiflorus complex containing three morphologically similar orchid species endemic to Australia.

Our genomic study provided insights into genetic diversity and structure of the $C$. aconitiflorus complex at fine-scale resolution. The results from the molecular analyses present a complex pattern that indicates occasional gene flow between C. aconitiflorus and $C$. barbarae. The apparent non-monophyly of the three species in the phylogenetic results is coherent with patterns expected in the presence of reticulation. The phylogenetic reconstruction showed genetically admixed samples of $C$. aconitiflorus and $C$. barbarae either towards the basal position of the main clade for each species comprising samples which exhibited no or low levels of admixture, or in intermediate position between the $C$. aconitiflorus and C. barbarae main clades. In the phylogenetic tree reconstruction, Corybas dowlingii clustered most closely to samples of C. aconitiflorus and C. barbarae for which genetic signatures of hybridisation were detected in the NeigborNet and Structure analysis. The NeighborNet and Structure analyses revealed conflicting phylogenetic signal and genetic admixture in several samples, providing evidence for occasional hybridisation and introgression between C. aconitiflorus and C. barbarae. In the NeighborNet analysis (Fig. 3), the majority of $C$. aconitiflorus and $C$. barbarae samples formed a cluster each, while all $C$. dowlingii samples were found in intermediate position, together with several C. aconitiflorus and $C$. barbarae samples. Further, the NeighborNet analyses indicated conflicting genetic signal for the latter $C$. aconitiflorus, $C$. barbarae and $C$. dowlingii samples, which is consistent with patterns expected in the presence of hybridisation and introgression. The Structure analysis revealed considerable genetic structure within the species complex with 
seven genetic groups, and detected genetic admixture in several $C$. aconitiflorus, $C$. barbarae and C. dowlingii samples (Fig. 4). Within C. aconitiflorus, the highest degrees of genetic admixture were found in areas where the distributional range overlaps with $C$. barbarae, whereas $C$. aconitiflorus populations from areas where $C$. barbarae was absent (i.e. in Ulverstone in Tasmania and five locations in Victoria) showed no or low levels of genetic admixture. Thus, the results of this study indicate occasional hybridisation and introgression between $C$. barbarae and $C$. aconitiflorus, and provide genetic evidence that $C$. dowlingii is of hybrid origin. However, the genetic results also showed that samples of $C$. aconitiflorus and $C$. barbarae, respectively, are genetically more similar than to the other species, with the exception of samples which exhibited genetic signatures of hybridisation. Notably, $C$. aconitiflorus and C. barbarae samples which did not show signatures of admixtures genetically distinct from the other species in all analyses. Furthermore, genetically pure samples from different populations of the same species consistently clustered more closely together than those from co-occurring populations of the other species. This indicates that the two species, $C$. aconitflorus and $C$. barbarae maintain genetic coherence despite occasional hybridisation in areas where they co-occur.

The detected signatures of hybridisation and introgression are also in line with the presence of intermediate morphological character states in this species complex, in particular in floral traits such as flower colour and size. The intermediate position of $C$. dowlingii in the NeighborNet graph as well as the clustering of $C$. dowlingii samples with $C$. barbarae samples in the Structure analysis and the signature of genetic admixture found in several $C$. aconitiflorus, C. dowlingii and C. barbarae samples in the Structure analysis, point to a hybrid origin of $C$. dowlingii. Notably, the study also uncovered signatures of hybridisation and introgression in individuals that did not exhibit the $C$. dowlingii morphotype and which were morphologically assigned to either $C$. aconitiflorus or $C$. barbarae. These results highlight existing challenges in interpreting morphological variation in the complex and thus in identifying hybrids and introgressed individuals based on morphological traits alone.

Based on the results of this genomic study, we propose to change the taxonomic status of $C$. dowlingii in accordance with Article 50 of the International Code of Nomenclature for algae, fungi, and plants (Turland et al. 2018) to reflect its hybrid origin, as follows:

Corybas $\times$ dowlingii D.L.Jones, The Orchadian 14(9): 419-420, f.1 (2004) (pro sp.).

\section{Assessment of conservation status of $C . \times$ dowlingii}


Based on the molecular results of this study, which indicate that $C . \times$ dowlingii is of hybrid origin, the question arises whether and to what extent the taxon may merit conservation. A recent review of conservation legislation found that legal definitions of species are quite flexible and can accommodate a range of infra-specific taxa and divergent populations (Coates et al. 2018). While traditionally the protection of pure, genetically distinct species that do not interbreed successfully have been favoured in conservation science and policy (Agapow et al. 2004), it is increasingly recognised that biological diversity generated by hybridisation can also hold conservation value (Allendorf et al. 2001; Agapow et al. 2004). While the evolutionary importance of hybridisation in the diversification of plants has long been recognised, recent genomic studies highlighted the prevalence of hybridisation in the natural world (Taylor and Larson 2019). Further, the detection of ancient hybridisation in genomic studies, which indicate that hybridisation occurred in many taxa at some point in the past, has led to a greater appreciation of the evolutionary importance of hybridisation and introgression and improves our understanding of potential long-term consequences of hybridisation (Taylor and Larson 2019). Hybridisation can lead to greater fitness compared to parental species, i.e. heterosis (hybrid vigour), and is seen as important evolutionary processes that promotes adaptation and speciation. Hybrids can exhibit novel adaptive traits that allow for increased ecosystem resilience to environmental stressors and can allow for the successful colonisation of novel habitats (Stebbins 1959). However, hybrids can also have negative impacts on biodiversity, in particular in cases where hybrids pose risks to the survival of their parental species or to other native vegetation (Rhymer and Simberloff 1996). Based on a review of species hybrids and their conservation or management, Jackiw et al. (Jackiw et al. 2015) strongly advocate for a case by case approach in assessing the conservation value of hybrids.

In the following, we will apply the framework to guide the conservation of species hybrids based on ethical and ecological considerations developed by Jackiw et al. (Jackiw et al. 2015) to assess the conservation value of $C . \times$ dowlingii. A key ecological consideration is whether the hybrid is likely to pose a risk to the survival of the parental species, for example through decreasing the genetic variability in parental species or by causing extinction through genetic assimilation as long-term consequences of recurrent hybridisation and introgression (Rhymer and Simberloff 1996). This is of particular importance in cases where parental species are already threatened by other factors. Corybas $\times$ dowlingii has only a narrow distribution whereas both parental species are common and occur over a large distributional range with both sympatric and allopatric distributions. From this perspective, the hybrid species $C . \times$ 
dowlingii as well as hybrids that occasionally form between the two parental species and which do not exhibit the $C$. dowlingii morphotype, are unlikely to negatively affect the longterm evolutionary persistence of the parental species.

Another consideration concerns species fitness as hybrid species exhibiting a higher fitness than the parental species may have detrimental effects either for the parental species or to other native species, as has been documented for example in invasive weeds (Stebbins 1959; Rhymer and Simberloff 1996). Corybas $\times$ dowlingii is only known from a few populations extending ca. $100 \mathrm{~km}$ from Bulahdelah to Freemans Waterhole in New South Wales, overlapping with the geographic distribution of the two parental species and occurring in the same habitat. Based on our ecological observations in the field, there is no indication of increased fitness of $C . \times$ dowlingii compared to its parental species. From this perspective, the hybrid species is also unlikely to negatively affect the survival of the parental species or other native vegetation.

An important consideration from an evolutionary perspective is that hybrids are often regarded as beneficial. They hold the potential to act as catalysts for speciation or more generally as pathway for evolution, for example in cases where hybrids exhibit novel properties such as in floral scent (Stökl et al. 2008; Vereecken et al. 2010), habitat requirements (Jacquemyn et al. 2012) or genome duplication and rearrangements (de Storme and Mason 2014). These novel traits might lead subsequently to the formation of a new species. Therefore, the maintenance of evolutionary processes becomes a key ethical consideration in the conservation of species hybrids (Jackiw et al. 2015). Given that $C$. $\times$ dowlingii is unlikely to pose a threat to the long-term survival of its parental species nor other native species, in the following we will examine possible beneficial aspects that may warrant the conservation of $C . \times$ dowlingii, such as the potential of the hybrid species to act as pathway for evolution.

In the New Caledonian hybrid species Corybas $\times$ halleanus E.Faria, a greater tolerance to lower humidity was observed for the hybrid species compared to its more moisture dependent parental species (Faria 2016). The hybrid species thus exhibits increased resilience to environmental stressors, which enables the hybrid to colonise novel habitat, thus rendering the conservation of this hybrid species beneficial. In contrast, $C . \times$ dowlingii is found in the same habitat as its parental species and growing sympatrically with C. barbarae (Jones 2004), thus not exhibiting novel habitat requirements.

In terms of pollination biology, observations on pollinators in the C. aconitiflorus complex are still scarce. While the pollination strategy of the genus has been regarded as food or brood 
deceptive based on observations from other Corybas species (Pridgeon et al. 2001), recent observations in C. aconitiflorus indicate that the species is food-rewarding (Kuiter and Findlater-Smith 2017). Fungus gnats of the genus Phthinia Winnertz 1863 (Mycetophilidae) were observed to visit the flowers to forage on the column mound which has been reported to exude nectar and females where found leaving the flowers with pollinia attached to their thorax (Kuiter and Findlater-Smith 2017). The repeated and directed visiting behaviour of the fungus gnats was regarded as indication that the fungus gnats are attracted through floral scent. Further, the plant-pollinator relationship was found to be specific in the Corybas populations in Victoria, where only one Phthinia species was observed to visit the flowers (Kuiter and Findlater-Smith 2017). However, the detection of genetically admixed individuals in our molecular study implies that the plant-pollinator relationship between C. aconitiflorus and C. barbarae is less specific and allows for occasional cross-pollination.

Orchid hybrids hold the potential to develop novel floral traits, which can result in reproductive isolation between the hybrid and parental species. This is of particular importance in orchids as the plant-pollinator interaction is often highly specific (Nilsson 1992). For example, the hybrid between two European Ophrys species was found to exhibit a novel floral scent which resulted in a pollinator shift (Vereecken et al. 2010). In the sun orchids (Thelymitra), hybrids are often found which have shifted their pollination system from outcrossing to obligatorily selfing (Jeanes 2004, 2009, 2013), which likewise presents an immediate reproductive isolation mechanism. Hence, pollination studies in $C . \times$ dowlingii are desirable to assess if the hybrid exhibits novel floral traits leading to reproductive isolation from its parental species. Likewise, changes in ploidy levels in association with hybridisation (allopolyploidisation) can also lead to immediate reproductive isolation between the hybrid and its parental species. Allopolyploid hybrid species tend to derive from parents that are evolutionarily more divergent than parents of homoploid hybrid species (Chapman and Burke 2007; Paun et al. 2009). In Corybas, cytogenetic studies found evidence for polyploidisation in the genus, e.g. in $C$. cheesmanii (Hook.f.) Kuntze with 2=54+2, pointing to a triploid or hexaploid origin (Dawson et al. 2007), however no chromosome counts are available for the C. $\times$ dowlingii nor its parental species. To assess possible reproductive isolation of $C . \times$ dowlingii from its parental species based on genome duplication or re-arrangements, cytogenetic studies in the $C$. aconitiflorus complex are required. However, given that hybridsation between closely related species is more likely to give rise to homoploid hybrids (Chapman and Burke 2007; Paun et al. 2009), we consider the establishment of reproductive 
isolation of $C . \times$ dowlingii from its parental species through genome duplication or rearrangements as unlikely.

Our overall assessment of key ecological and societal considerations indicated a low conservation concern for $C . \times$ dowlingii and highlighted areas for further studies to assess the degree of reproductive isolation of $C . \times$ dowlingii from its parental species to increase our understanding of the potential evolutionary fate of this species. In an environment of limited financial resources, it is of key importance to consider whether it is ethical to direct conservation funds and effort to hybrid species. In the case of $C . \times$ dowlingii, our overall assessment under the current available evidence points toward a low priority for conservation of the hybrid species, in particular considering that the two parental species are common and tend to hybridise occasionally. Hence, the maintenance of evolutionary processes that may result in the emergence of novel traits driving further diversification appears warranted in this species complex without particular conservation emphasis on the hybrid species $C$. $\times$ dowlingii. Based on the results of this study, we regard the conservation status of $C . \times$ dowlingii of 'least concern' and recommend changing its current conservation status in the threatened species legislations of New South Wales and Australia accordingly.

\section{Conclusions}

This conservation genomic study clarified taxonomic delimitation in the C. aconitiflorus complex and provided molecular evidence for occasional hybridisation and introgression between C. aconitiflorus and C. barbarae. Corybas dowlingii was found to be of hybrid origin and its taxonomic status was changed to $C . \times$ dowlingii to reflect this. Based on our assessment of the conservation status of $C . \times$ dowlingii considering key ecological and ethical aspects, we conclude that the conservation status of $C . \times$ dowlingii is of least concern and recommend this to be reflected in the Australian legislation at state and federal level.

\section{References}

Agapow PM, Bininda-Emonds ORP, Crandall KA, et al (2004) The impact of species concept on biodiversity studies. Q Rev Biol 79:161-179. https://doi.org/10.1086/383542

Ahrens CW, Supple MA, Aitken NC, et al (2017) Genomic diversity guides conservation strategies among rare terrestrial orchid species when taxonomy remains uncertain. Ann Bot-London 119:1267-1277

Allendorf FW, Leary RF, Spruell P, Wenburg JK (2001) The problems with hybrids: setting conservation guidelines. Trends Ecol Evol 16:613-622.

https://doi.org/10.1016/S0169-5347(01)02290-X 
AVH (2018) Australian Virtual Herbarium. Council of Heads of Australasian Herbaria. http://avh.chah.org.au. Accessed 17 June 2018

Baird NA, Etter PD, Atwood TS, et al (2008) Rapid SNP discovery and genetic mapping using sequenced RAD markers. PLOS One 3:e3376

Bateman RM, Sramko G, Paun O (2018) Integrating restriction site-associated DNA sequencing (RAD-seq) with morphological cladistic analysis clarifies evolutionary relationships among major species groups of bee orchids. Ann Bot-London 121:85105

Beheregaray LB, Pfeiffer LV, Attard CRM, et al (2017) Genome-wide data delimits multiple climate-determined species ranges in a widespread Australian fish, the golden perch (Macquaria ambigua). Mol Phylogenet Evol 111:65-75. https://doi.org/10.1016/j.ympev.2017.03.021

Brandrud MK, Baar J, Lorenzo MT, et al (2019a) Phylogenomic relationships of diploids and the origins of allotetraploids in Dactylorhiza (Orchidaceae). Syst Biol. https://doi.org/10.1093/sysbio/syz035

Brandrud MK, Paun O, Lorenz R, et al (2019b) Restriction-site associated DNA sequencing supports a sister group relationship of Nigritella and Gymnadenia (Orchidaceae). Mol Phylogenet Evol 136:21-28. https://doi.org/10.1016/j.ympev.2019.03.018

Catchen J, Hohenlohe PA, Bassham S, et al (2013) Stacks: an analysis tool set for population genomics. Mol Ecol 22:3124-3140. https://doi.org/10.1111/mec.12354

Catchen JM, Amores A, Hohenlohe P, et al (2011) Stacks: building and genotyping loci de novo from short-read sequences. G3-Genes Genom Genet 1:171-182. https://www.ncbi.nlm.nih.gov/pmc/articles/PMC3276136/pdf/171.pdf

Chapman MA, Burke JM (2007) Genetic divergence and hybrid speciation. Evolution 61:1773-1780. https://doi.org/10.1111/j.1558-5646.2007.00134.x

Chase MW, Cameron KM, Freudenstein JV, et al (2015) An updated classification of Orchidaceae. Botanical Journal of the Linnean Society 177:151-174

Clements MA, Jones DL, Sharma IK, et al (2002) Phylogenetics of Diurideae (Orchidaceae) based on the internal transcribed spacer (ITS) regions of nuclear ribosomal DNA. Lindleyana 17:135-171

Coates DJ, Byrne M, Moritz C (2018) Genetic diversity and conservation units: dealing with the species-population continuum in the age of genomics. Front Ecol Evol 6:. https://doi.org/10.3389/fevo.2018.00165

Cozzolino S, Nardella AM, Impagliazzo S, et al (2006) Hybridization and conservation of Mediterranean orchids: Should we protect the orchid hybrids or the orchid hybrid zones? Biol Conserv 129:14-23. https://doi.org/10.1016/j.biocon.2005.09.043

Cozzolino S, Scopece G, Roma L, Schlueter PM (2019) Different filtering strategies of genotyping-by-sequencing data provide complementary resolutions of species boundaries and relationships in a clade of sexually deceptive orchids. Journal of Systematics and Evolution. https://doi.org/10.1111/jse.12493 
Cribb PJ, Kell SP, Dixon KW, Barrett RL (2003) Orchid conservation: a global perspective. In: Dixon KW, Kell SP, Barrett RL, Cribb PJ (eds) Orchid conservation. Natural History Publications, Kota Kinabalu, Sabah, pp 1-24

Davey JW, Hohenlohe PA, Etter PD, et al (2011) Genome-wide genetic marker discovery and genotyping using next-generation sequencing. Nat Rev Genet 12:499-510

De Queiroz K (2007) Species concepts and species delimitation. Systematic Biology 56:879886. https://doi.org/10.1080/10635150701701083

de Storme N, Mason A (2014) Plant speciation through chromosome instability and ploidy change: cellular mechanisms, molecular factors and evolutionary relevance. Current Plant Biology 1:10-33

Dressler RL (1981) The orchids: natural history and classification. Harvard Univ Press, Cambridge

Earl DA, vonHoldt BM (2012) STRUCTURE HARVESTER: a website and program for visualizing STRUCTURE output and implementing the Evanno method. Conservation Genetics Resources 4:359-361. https://doi.org/10.1007/s12686-011-9548-7

Eaton DAR, Overcast I (2016) iPYRAD: interactive assembly and analysis of RADseq data sets. http://ipyrad.readthedocs.io/

Eaton DAR, Ree RH (2013) Inferring phylogeny and introgression using RADseq data: an example from flowering plants (Pedicularis: Orobanchaceae). Syst Biol Syst Biol 62:689-706

Edgar RC (2010) Search and clustering orders of magnitude faster than BLAST.

Bioinformatics (Oxford, England) 26:2460-1. https://doi.org/10.1093/bioinformatics/btq461

Edgar RC (2004) MUSCLE: a multiple sequence alignment method with reduced time and space complexity. BMC Bioinformatics 5:1-19

EPBC (1999) Environment Protection and Biodiversity Conservation Act List of Threatened Flora. http://www.environment.gov.au/cgibin/sprat/public/publicthreatenedlist.pl?wanted=flora. Accessed 14 January 2016

Escudero M, Eaton DAR, Hahn M, Hipp AL (2014) Genotyping-by-sequencing as a tool to infer phylogeny and ancestral hybridization: a case study in Carex (Cyperaceae). Mol Phylogenet Evol 79:359-367

Evanno G, Regnaut S, Goudet J (2005) Detecting the number of clusters of individuals using the software STRUCTURE: a simulation study. Molecular Ecology 14:2611-2620. https://doi.org/10.1111/j.1365-294X.2005.02553.x

Faria E (2016) Diversity in the genus Corybas Salisb. (Orchidaceae, Diurideae) in New Caledonia. Adansonia 38:175-198. https://doi.org/10.5252/a2016n2a4

Govaerts R, Bernet P, Kratochvil K, et al (2017) World checklist of Orchidaceae. http://wscp.science.kew.org. Accessed 10 November 2017 
Herrera S, Shank TM (2016) RAD sequencing enables unprecedented phylogenetic resolution and objective species delimitation in recalcitrant divergent taxa. Mol Phylogenet Evol 100:70-79

Hipp AL, Manos PS, Gonzalez-Rodriguez A, et al (2018) Sympatric parallel diversification of major oak clades in the Americas and the origins of Mexican species diversity. New Phytol 217:439-452

Hopper SD (2009) Taxonomic turmoil down-under: recent developments in Australian orchid systematics. Annals of Botany 104:447-455. https://doi.org/10.1093/Aob/Mcp090

Hubisz MJ, Falush D, Stephens M, Pritchard JK (2009) Inferring weak population structure with the assistance of sample group information. Molecular Ecology Resources 9:1322-1332. https://doi.org/10.1111/j.1755-0998.2009.02591.x

Huson DH, Bryant D (2006) Application of phylogenetic networks in evolutionary studies. Molecular Biology and Evolution 23:254-267. https://doi.org/10.1093/molbev/msj030

Jackiw RN, Mandil G, Hager HA (2015) A framework to guide the conservation of species hybrids based on ethical and ecological considerations. Conserv Biol 29:1040-1051. https://doi.org/10.1111/cobi.12526

Jacquemyn H, Brys R, Honnay O, et al (2012) Nonrandom spatial structuring of orchids in a hybrid zone of three Orchis species. New Phytologist 193:454-464

Jeanes JA (2004) A revision of the Thelymitra pauciflora R.Br. (Orchidaceae) complex in Australia. Muelleria 19:19-79

Jeanes JA (2009) Resolution of the Thelymitra variegata (Orchidaceae) complex of southern Australia and New Zealand. Muelleria 27:149-170

Jeanes JA (2013) An overview of the Thelymitra nuda (Orchidaceae) complex in Australia including the description of six new species. Muelleria 31:3-30

Jones DL (2004) Corybas dowlingii (Orchidaceae), a new species from north-eastern New South Wales. The Orchadian 14:419-420

Jones DL (2006) A complete guide to native orchids of Australia, including the Island Territories. Reed New Holland, Sydney

Jones JC, Fan SH, Franchini P, et al (2013) The evolutionary history of Xiphophorus fish and their sexually selected sword: a genome-wide approach using restriction siteassociated DNA sequencing. Mol Ecol 22:2986-3001

Kores PJ, Molvray M, Weston PH, et al (2001) A phylogenetic analysis of Diurideae (Orchidaceae) based on plastid DNA sequence data. American Journal of Botany 88:1903-1914

Kuiter RH, Findlater-Smith MJ (2017) Initial observations on the pollination of Corybas (Orchidaceae) by fungas-gnats (Diptera: Sciaroidea). 5:1-19 
Lemmon EM, Lemmon AR (2013) High-throughput genomic data in systematics and phylogenetics. Annu Rev Ecol Evol S 44:99-121. https://doi.org/10.1146/annurevecolsys-110512-135822

The Plant List (2018) The Plant List v. 1.1. http://www.theplantlist.org. Accessed 13 March 2018

Lyon SP (2014) Molecular systematics, biogeography, and mycorrhizal associations in the Acianthinae (Orchidaceae), with focus on the genus Corybas. University of Wisconsin-Madison

Miller MR, Dunham JP, Amores A, et al (2007) Rapid and cost-effective polymorphism identification and genotyping using restriction site associated DNA (RAD) markers. Genome Res 17:240-248

Mort ME, Crawford DJ, Kelly JK, et al (2015) Multiplexed-shotgun-genotyping data resolve phylogeny within a very recently derived insular lineage. Am J Bot 102:634-641. https://doi.org/10.3732/ajb.1400551

Nauheimer L, Schley R, Clements MA, et al (2018) Australasian orchid biogeography at contintal scale: molecular phylogenetic insights from the Sun Orchids (Thelymitra, Orchidaceae). Mol Phylogenet Evol 127:304-319. https://doi:10.1016/j.ympev.2018.05.031

Nilsson LA (1992) Orchid pollination biology. Trends Ecol Evol 7:255-259. https://doi.org/10.1016/0169-5347(92)90170-G

Paun O, Forest F, Fay MF, Chase MW (2009) Hybrid speciation in angiosperms: parental divergence drives ploidy. New Phytol 182:507-518. https://doi.org/10.1111/j.14698137.2009.02767.x

Peterson BK, Weber JN, Kay EH, et al (2012) Double Digest RADseq: an inexpensive method for de novo SNP discovery and genotyping in model and non-model species. PLOS One 7: e37135. https://doi.org/10.1371/journal.pone.0037135

Pinheiro F, De Barros F, Palma-Silva C, et al (2010) Hybridization and introgression across different ploidy levels in the Neotropical orchids Epidendrum fulgens and $E$. puniceoluteum (Orchidaceae). Mol Ecol 19:3981-94. https://doi.org/10.1111/j.1365294X.2010.04780.x

Pridgeon AM, Cribb PJ, Chase MW (2001) Genera Orchidacearum Vol 6 Orchidoideae (Part 1), 2 edn. Oxford Univ Pr, Oxford

Pritchard JK, Stephens M, Donnelly P (2000) Inference of population structure using multilocus genotype data. Genetics 155:945-959

Rhymer JM, Simberloff D (1996) Extinction by hybridization and introgression. Annu Rev Ecol Syst 27:83-109

Stamatakis A (2014) RAxML Version 8: a tool for phylogenetic analysis and post-analysis of large phylogenies. Bioinformatics 30:1312.

https://doi.org/10.1093/bioinformatics/btu033 
bioRxiv preprint doi: https://doi.org/10.1101/2020.01.22.916080; this version posted January 26,2020 . The copyright holder for this preprint (which was not certified by peer review) is the author/funder, who has granted bioRxiv a license to display the preprint in perpetuity. It is made available under aCC-BY-NC-ND 4.0 International license.

Stamatakis A, Hoover P, Rougemont J (2008) A rapid bootstrap algorithm for the RAxML web servers. Syst Biol 57:758-771

Stebbins GL (1959) The role of hybridisation in evolution. Proceedings of the American Philosphical Society 103:231-251

Stökl J, Schlüter PM, Stuessy TF, et al (2008) Scent variation and hybridization cause the displacement of a sexually deceptive orchid species. Am J Bot 95:472-481. https://doi.org/10.3732/ajb.95.4.472

Takahashi T, Nagata N, Sota T (2014) Application of RAD-based phylogenetics to complex relationships among variously related taxa in a species flock. Mol Phylogenet Evol 80:137-144

Taylor SA, Larson EL (2019) Insights from genomes into the evolutionary importance and prevalence of hybridization in nature. Nat Ecol Evol 3:170-177. https://doi.org/10.1038/s41559-018-0777-y

TSCA (1995) Threatened Species Conservation Act No. 101 New South Wales Parliamentary Counsel's Office. https://www.legislation.nsw.gov.au/ /pdf/view/act/1995/101/whole. Accessed 18 December 2019.

Turland NJ, Wiersema JH, Barrie FR, Greuter W, Hawksworth DL, Herendeen PS, Knapp S, Kusber W-H, Li D-Z, Marhold K, May TW, McNeill J, Monro AM, Prado J, Price MJ, Smith GF (eds.) 2018: International Code of Nomenclature for algae, fungi, and plants (Shenzhen Code) adopted by the Nineteenth International Botanical Congress Shenzhen, China, July 2017. Regnum Vegetabile 159. Koeltz Botanical Books, Glashütten. DOI https://doi.org/10.12705/Code.2018

Vereecken NJ, Cozzolino S, Schiestl FP (2010) Hybrid floral scent novelty drives pollinator shift in sexually deceptive orchids. BMC Evol Biol 10:103. https://doi.org/10.1186/1471-2148-10-103

Wagner ND, Gramlich S, Horandl E (2018) RAD sequencing resolved phylogenetic relationships in European shrub willows (Salix L. subg. Chamaetia and subg. Vetrix) and revealed multiple evolution of dwarf shrubs. Ecol Evol 8:8243-8255. https://doi.org/10.1002/ece3.4360

Wagner CE, Keller I, Wittwer S, et al (2013) Genome-wide RAD sequence data provide unprecedented resolution of species boundaries and relationships in the Lake Victoria cichlid adaptive radiation. Mol Ecol 22:787-798

Weising K, Nybom H, Wollf K, Meyer W (2005) DNA fingerprinting techniques in plants: principles, methods, and applications. CRC Press, Taylor and Francis Group, Boca Raton

Figure and Table captions 


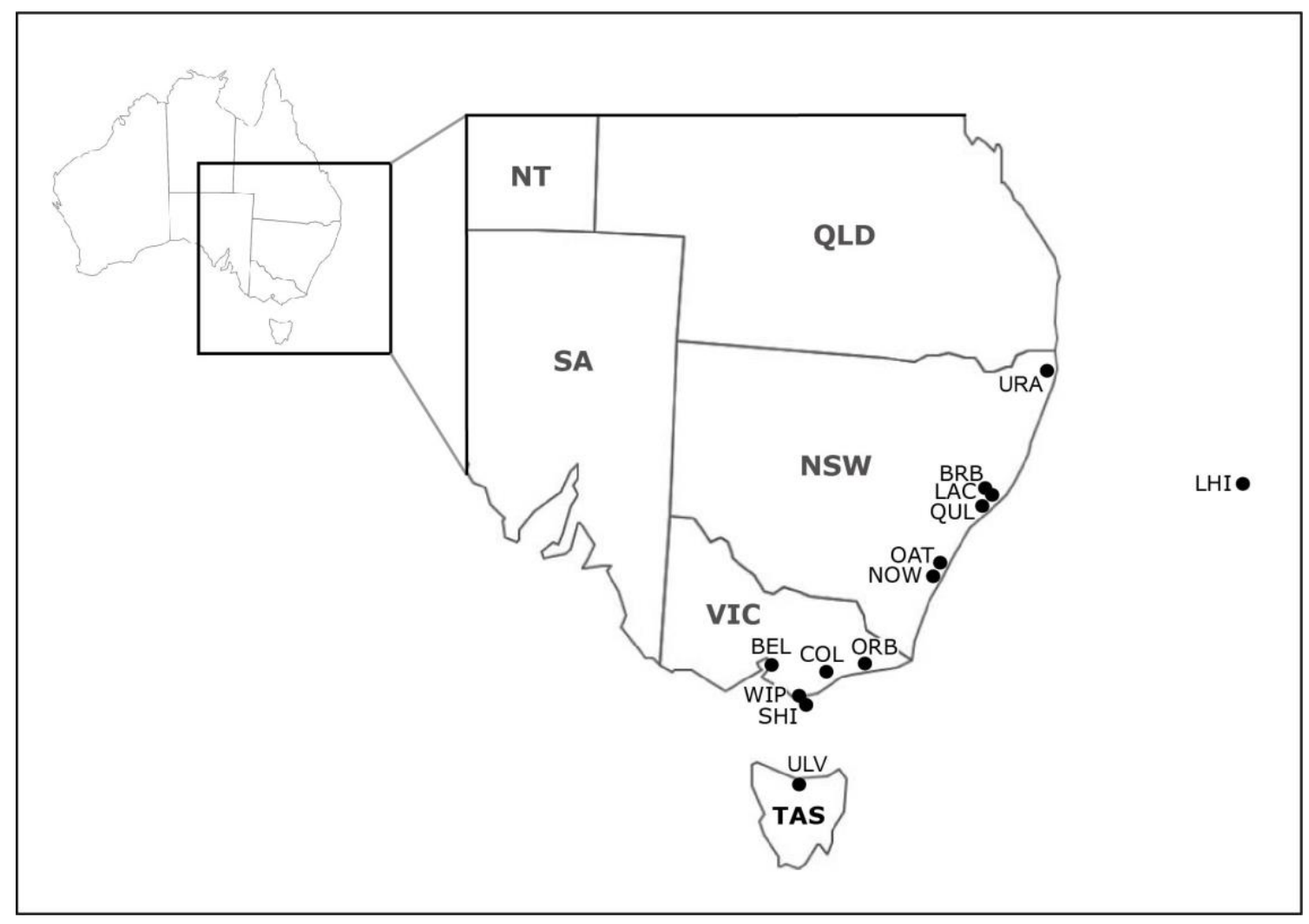

Fig. 1 Sampling locations for study of genomic diversity of the C. aconitiflorus complex in southeastern Australia. Australian state abbreviations in bold. BEL: Belgrave South; BRB: Broken Bago; COL: Colquhoun; LAC: Lake Cathie; LHI: Lord Howe Island; NOW: Nowra; OAT: Oatly Park; ORB: Orbost; QUL: Queens Lake; SHI: Shallow Inlet; URA: Uralba Nature Reserve; ULV: Ulverstone; WIP: Wilson Promontory 
bioRxiv preprint doi: https://doi.org/10.1101/2020.01.22.916080; this version posted January 26, 2020. The copyright holder for this preprint (which was not certified by peer review) is the author/funder, who has granted bioRxiv a license to display the preprint in perpetuity. It is made available under aCC-BY-NC-ND 4.0 International license.

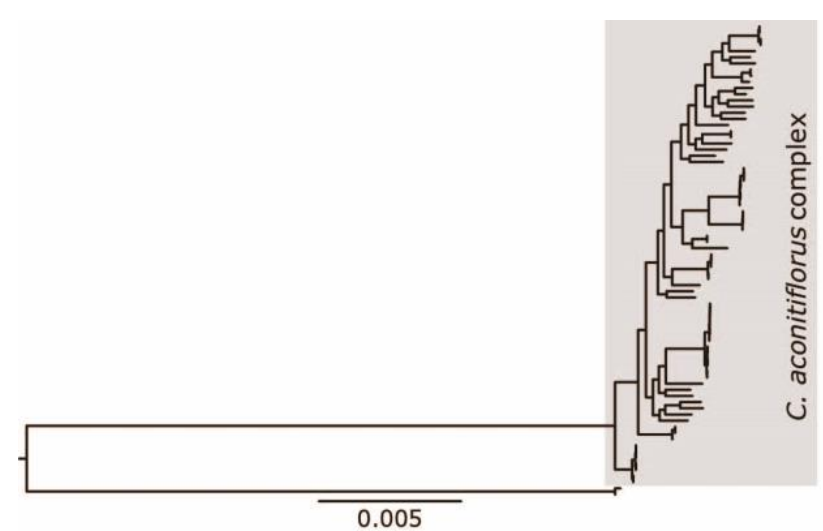

C. aconitiflorus G04708 ULV C. aconitiflorus G04662 ULV C. aconitiflorus G04668 ULV C. aconitiflorus G04687 WIP

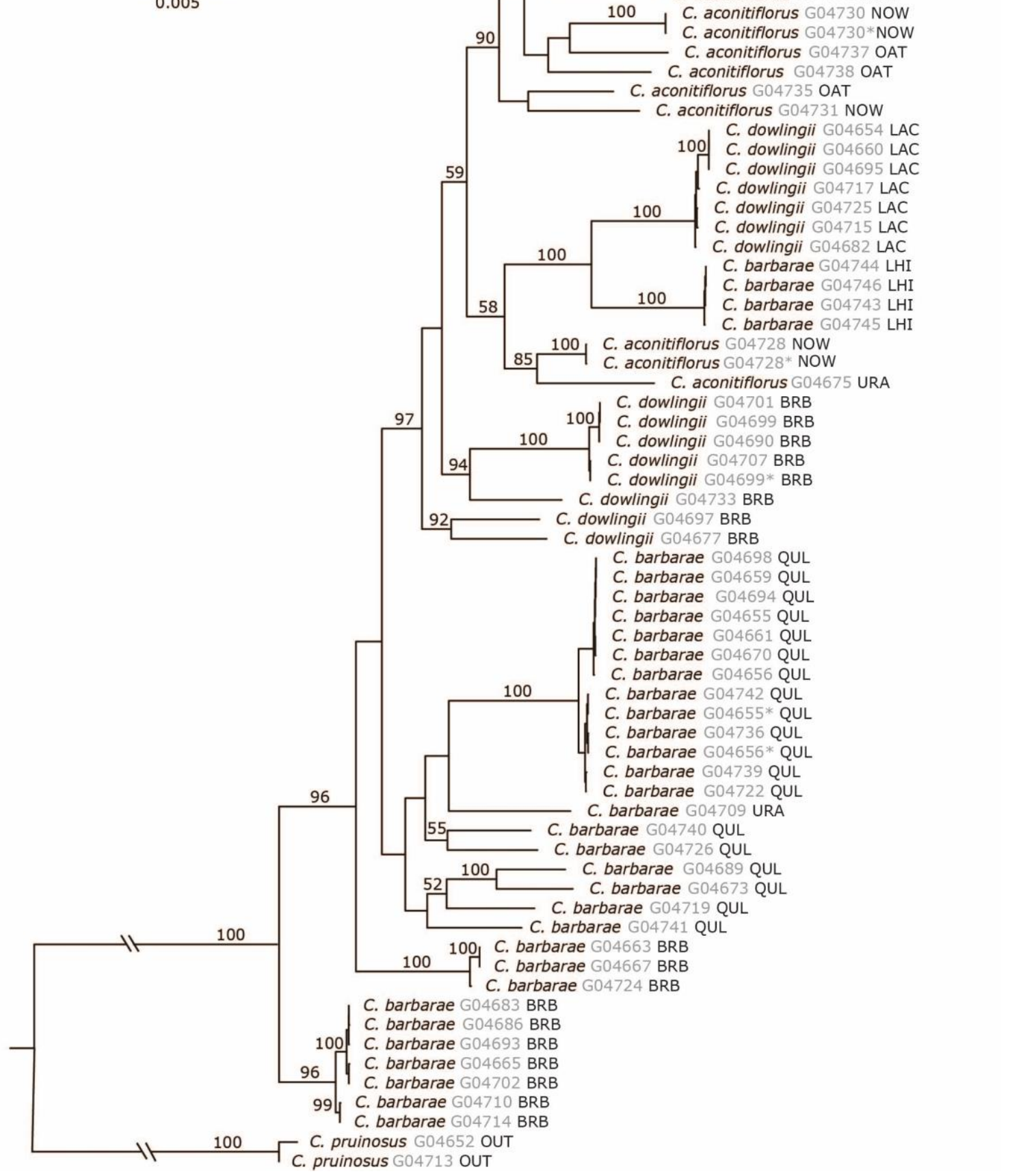

Fig. 2 Maximum likelihood phylogeny of the Corybas aconitiflorus complex based on 12,420 ddRAD loci (m20 dataset including outgroup). BEL: Belgrave South; BRB: Broken Bago; 
bioRxiv preprint doi: https://doi.org/10.1101/2020.01.22.916080; this version posted January 26, 2020. The copyright holder for this preprint (which was not certified by peer review) is the author/funder, who has granted bioRxiv a license to display the preprint in perpetuity. It is made available under aCC-BY-NC-ND 4.0 International license.

COL: Colquhoun; LAC: Lake Cathie; LHI: Lord Howe Island; NOW: Nowra; OAT: Oatly Park; ORB: Orbost; QUL: Queens Lake; SHI: Shallow Inlet; URA: Uralba Nature Reserve; ULV: Ulverstone; WIP: Wilson Promontory. Bootstrap support values above 50 are given above branches. Duplicate samples are marked with an asterisk

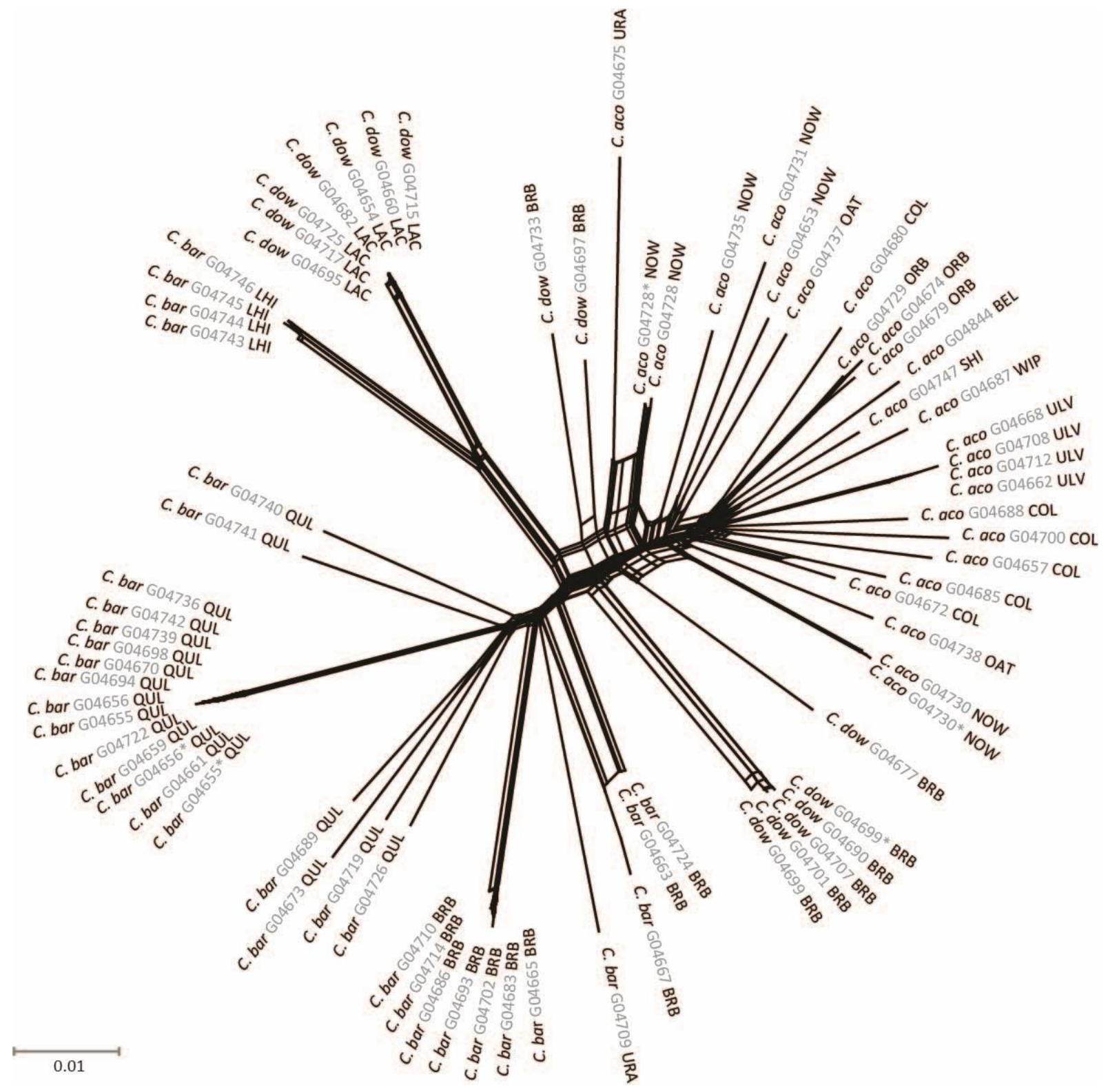

Fig. 3 NeighborNet network for Corybas aconitiflorus complex based on 4,293 unlinked SNPs (m20 dataset excluding outgroup). C. aco: Corybas aconitiflorus; C. bar: Corybas barbarae; C. dow: Corybas dowlingii. BEL: Belgrave South; BRB: Broken Bago; COL: Colquhoun; LAC: Lake Cathie; LHI: Lord Howe Island; NOW: Nowra; OAT: Oatly Park; ORB: Orbost; QUL: Queens Lake; SHI: Shallow Inlet; URA: Uralba Nature Reserve; ULV: Ulverstone; WIP: Wilson Promontory. Duplicate samples are marked with an asterisk 


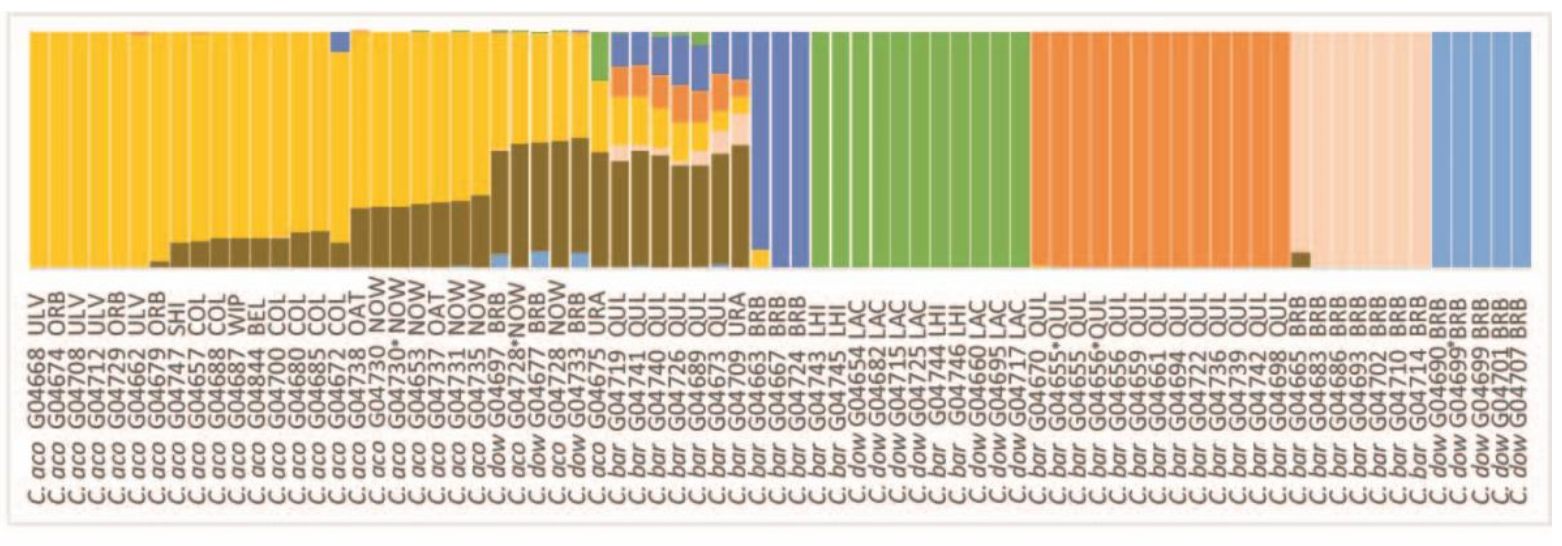

Fig. 4 Genetic structure of Corybas aconitiflorus complex based on Structure analysis of 13,708 unlinked SNPs (m70 dataset excluding outgroup) for the optimal K value of seven genetic clusters. C. aco: Corybas aconitiflorus; C. bar: Corybas barbarae; C. dow: Corybas dowlingii. BEL: Belgrave South; BRB: Broken Bago; COL: Colquhoun; LAC: Lake Cathie; LHI: Lord Howe Island; NOW: Nowra; OAT: Oatly Park; ORB: Orbost; QUL: Queens Lake; SHI: Shallow Inlet; URA: Uralba Nature Reserve; ULV: Ulverstone; WIP: Wilson Promontory. Duplicate samples are marked with an asterisk

\section{Tables and table captions}

Tab. 1 Material studied. AU: Australia; CNS: Australian Tropical Herbarium; ORG: Orchid Research Group, Centre for Australian Plant Biodiversity Research, Canberra; 1 sample used for ddRADseq establishment phase; duplicate samples are marked with an asterisk

\begin{tabular}{|c|c|c|c|c|}
\hline Corybas species & $\begin{array}{l}\text { Collection } \\
\text { number }\end{array}$ & DNA number & Provenance & $\begin{array}{l}\text { Proven } \\
\text { code }\end{array}$ \\
\hline C. aconitiflorus Salisb. & ORG 7362 & CNS_G04675 & $\begin{array}{l}\text { AU: New South Wales, North Coast; property of C \& } \\
\text { P Charlie, adjoining Uralba Nature Reserve }\end{array}$ & URA \\
\hline C. aconitiflorus Salisb. & ORG 7364 & CNS_G047321 & $\begin{array}{l}\text { AU: New South Wales, Central Coast; Bugong near } \\
\text { Nowra }\end{array}$ & NOW \\
\hline C. aconitiflorus Salisb. & ORG 7365 & CNS_G04735 & $\begin{array}{l}\text { AU: New South Wales, South Coast; Falls Creek near } \\
\text { Nowra }\end{array}$ & NOW \\
\hline C. aconitiflorus Salisb. & ORG 7366 & $\begin{array}{l}\text { CNS_G04728 } \\
\text { CNS_G04728* }\end{array}$ & $\begin{array}{l}\text { AU: New South Wales, South Coast; Turpentine Rd, } \\
\text { near Nowra }\end{array}$ & NOW \\
\hline C. aconitiflorus Salisb. & ORG 7367 & $\begin{array}{l}\text { CNS_G04730 } \\
\text { CNS_G04730* }\end{array}$ & $\begin{array}{l}\text { AU: New South Wales, South Coast; Wool Rd near } \\
\text { Nowra }\end{array}$ & NOW \\
\hline C. aconitiflorus Salisb. & ORG 7368 & CNS_G04731 & $\begin{array}{l}\text { AU: New South Wales, South Coast; Myola near } \\
\text { Nowra }\end{array}$ & NOW \\
\hline
\end{tabular}




\section{C. aconitiflorus Salisb. \\ C. aconitiflorus Salisb. \\ C. aconitiflorus Salisb. \\ C. aconitiflorus Salisb. \\ C. aconitiflorus Salisb. \\ C. aconitiflorus Salisb.}

C. aconitiflorus Salisb.

C. aconitiflorus Salisb.

C. aconitiflorus Salisb.

C. aconitiflorus Salisb.

C. aconitiflorus Salisb.

C. aconitiflorus Salisb.

C. aconitiflorus Salisb.

C. aconitiflorus Salisb.

C. aconitiflorus Salisb.

C. aconitiflorus Salisb.

C. aconitiflorus Salisb.

C. aconitiflorus Salisb.

C. aconitiflorus Salisb.

C. barbarae D.L.Jones
ORG 7369

CNS_G04653

ORG 7361A

CNS_G04668

ORG 7361B

CNS_G04662

ORG 7361C

CNS_G04712

ORG 7361D

CNS_G04708

ORG 7373B

CNS_G04687

Turner 2063A

CNS_G04680

Turner 2063B

CNS_G04657

Turner 2063C

CNS_G04700

CNS_G04672

Turner 2064A

Turner 2064B

CNS_G04688

Turner 2064C

CNS G04685

Turner 2065A

CNS_G04729

: Victoria, Gippsland; Near Circle Break Track $14.5 \mathrm{~km} \mathrm{~W}$ of Orbost (S of Princes Highway)

AU: Victoria, Gippsland; Near Circle Break Track $14.5 \mathrm{~km} \mathrm{~W}$ of Orbost (S of Princes Highway)

AU: Victoria, Gippsland; Near Circle Break Track $14.5 \mathrm{~km} \mathrm{~W}$ of Orbost (S of Princes Highway)

ORB

AU: New South Wales, Central Coast; Oatley Park, George River

OAT

AU: New South Wales, Central Coast; Oatley Park, George River

OAT

AU: Victoria, Gippsland; Shallow Inlet

SHI

AU: Victoria, Gippsland; Belgrave South

BEL

CNS_G04655

CNS_G04655*

AU: New South Wales, North Coast; Queens Lake, Lakewood 


\section{C. barbarae D.L.Jones \\ C. barbarae D.L.Jones}

C. barbarae D.L.Jones

C. barbarae D.L.Jones

C. barbarae D.L.Jones

C. barbarae D.L.Jones

C. barbarae D.L.Jones

C. barbarae D.L.Jones

C. barbarae D.L.Jones

C. barbarae D.L.Jones

C.barbarae D.L.Jones

C.s barbarae D.L.Jones

C. barbarae D.L.Jones

C. barbarae D.L.Jones

C. barbarae D.L.Jones

C. barbarae D.L.Jones

C. barbarae D.L.Jones

C. barbarae D.L.Jones

C. barbarae D.L.Jones

C. barbarae D.L.Jones
CNS_G04736

ORG 7357G

CNS_G04670

ORG 7357G

CNS G04694

ORG 7357H

CNS_G04661

ORG 7357I

CNS G04698

ORG 7357J

CNS_G04722

CNS_G04656

ORG 7357K

CNS_G04656*

ORG 7357L

CNS_G04740

ORG 7357M

CNS_G046711

ORG 7357N

CNS_G04689

ORG 7357o

CNS_G04673

ORG 7357P

CNS_G04659

ORG 7357R

CNS_G04739

ORG 7357T

CNS_G04741

ORG 7357U

CNS_G04719

ORG 7357V

CNS_G04726

CNS_G04667

ORG 7359A

ORG 7359B

CNS_G04724

ORG 7359C

CNS G04714

ORG 7359D
AU: New South Wales, North Coast; Queens Lake, Lakewood

QUL

AU: New South Wales, North Coast; Queens Lake, Lakewood

QUL

AU: New South Wales, North Coast; Queens Lake, Lakewood

QUL

AU: New South Wales, North Coast; Queens Lake, Lakewood

QUL

AU: New South Wales, North Coast; Queens Lake, Lakewood

QUL

AU: New South Wales, North Coast; Queens Lake, Lakewood

QUL

AU: New South Wales, North Coast; Queens Lake, Lakewood

QUL

AU: New South Wales, North Coast; Queens Lake, Lakewood

QUL

AU: New South Wales, North Coast; Queens Lake, Lakewood

QUL

AU: New South Wales, North Coast; Queens Lake, Lakewood

QUL

AU: New South Wales, North Coast; Queens Lake, Lakewood

QUL

AU: New South Wales, North Coast; Queens Lake, Lakewood

QUL

AU: New South Wales, North Coast; Queens Lake, Lakewood

AU: New South Wales, North Coast; Queens Lake, Lakewood

QUL

AU: New South Wales, North Coast; Queens Lake, Lakewood

QUL

AU: New South Wales, North Coast; Queens Lake, Lakewood

AU: New South Wales, North Coast; Broken Bago State Forest, between Herons Creek \& Wauchope

BRB

AU: New South Wales, North Coast; Broken Bago State Forest, between Herons Creek \& Wauchope

$\mathrm{BRB}$

AU: New South Wales, North Coast; Broken Bago State Forest, between Herons Creek \& Wauchope

$\mathrm{BRB}$

AU: New South Wales, North Coast; Broken Bago State Forest, between Herons Creek \& Wauchope 
AU: New South Wales, North Coast; property of C \& P Charlie, ajoining Uralba Nature Reserve

AU: New South Wales, North Coast; Edge of Queens Lake, Lakewood

AU: Lord Howe Island: Ridge between Kim's Lookout and Malabar

AU: Lord Howe Island: Ridge between Kim's Lookout and Malabar

AU: Lord Howe Island: Ridge between Kim's Lookout and Malabar

AU: Lord Howe Island: Ridge between Kim's Lookout and Malabar 
Tab. 2. Statistics for the ddRAD dataset for the $C$. aconitiflorus complex a) including the outgroup (C. pruinosus, 2 samples) and b) excluding the outgroup resulting from the different filtering thresholds in the ipyrad pipeline for loci shared by minimum number of samples. pis: parsimony informative characters, bp: base pairs, m: minimum number of samples

a) C. aconitiflorus complex including outgroup (C. pruinosus) Average \# filtered reads: 2.98 Mio (+/- 1.01) per sample

\begin{tabular}{lll}
\hline Filtering threshold & m20 & m70 \\
\hline \#RAD loci & 12,420 & 3,597
\end{tabular}




\begin{tabular}{lll} 
\#variable sites & 54,177 & 17,378 \\
\#pis & 36,486 & 12,302 \\
\#aligned bp & $1,682,315$ & 487,474 \\
missing data* & $37.66 \%$ & $4.55 \%$ \\
\hline
\end{tabular}

*Proportion of gaps and undetermined bases in DNA sequence alignment

b) C. aconitiflorus complex (ingroup)

Average \# filtered reads: 3,01 Mio (+/-1,01)

\begin{tabular}{lll}
\hline Filtering threshold & m20 & m70 \\
\hline \#RAD loci & 14,915 & 4,293 \\
\#variable sites & 60,489 & 18,828 \\
\#pis & 39,470 & 12,252 \\
\#unlinked SNPs & 13,708 & 4,066 \\
\#aligned bp & $1,967,151$ & 581,128 \\
missing data* & $36.79 \%$ & $2.30 \%$ \\
\hline *Proportion of gaps and undetermined bases in DNA sequence alignment
\end{tabular}

\section{Online Resources}

Online Resource 1. Maximum likelihood phylogeny of the Corybas aconitiflorus complex based on 3,597 ddRAD loci (m70 dataset including outgroup).

Online Resource 2. NeighborNet network for Corybas aconitiflorus complex based on 4,066 unlinked SNPs (m70 dataset excluding outgroup).

Online Resource 3. Genetic structure of Corybas aconitiflorus complex based on Structure analysis of 13,708 unlinked SNPs (m20 dataset excluding outgroup) for the optimal $\mathrm{K}$ value of seven genetic clusters. 